\title{
Erratum to: Tubulointerstitial immune complex nephritis in a patient with systemic lupus erythematosus: role of peritubular capillaritis with immune complex deposits in the pathogenesis of the tubulointerstitial nephritis
}

Satoshi Hayakawa • Kimimasa Nakabayashi •

Miho Karube • Yoshihiro Arimura •

Akinori Soejima $\cdot$ Akira Yamada $\cdot$ Yasunori Fujioka

Published online: 24 June 2011

(C) Japanese Society of Nephrology 2011

Erratum to: Clin Exp Nephrol (2006) 10:146-151

DOI 10.1007/s10157-006-0405-z

The correct name of the fourth author should be given as Yoshihiro Arimura, not Yoshiro Arimura.

The online version of the original article can be found under doi:10.1007/s10157-006-0405-z.

S. Hayakawa $\cdot$ K. Nakabayashi $(\bowtie) \cdot$ M. Karube .

Y. Arimura $\cdot$ A. Soejima $\cdot$ A. Yamada

First Department of Internal Medicine, Kyorin University School of Medicine, 6-20-2 Shinkawa, Mitaka, Tokyo 181-0086, Japan e-mail: kimimasa@kyorin-u.ac.jp

Y. Fujioka

Department of Pathology, Kyorin University School

of Medicine, Tokyo, Japan 